\title{
BMJ Effectiveness of nurse home-visiting Open for disadvantaged families: results of a natural experiment
}

\author{
Michael Gifford Sawyer, ${ }^{1,2}$ Linda Frost, ${ }^{2}$ Kerrie Bowering, ${ }^{3}$ John Lynch $^{4,5}$
}

To cite: Sawyer MG, Frost L, Bowering $\mathrm{K}$, et al.

Effectiveness of nurse homevisiting for disadvantaged families: results of a natural experiment. BMJ Open 2013:3:e002720

doi:10.1136/bmjopen-2013002720

- Prepublication history and additional material for this paper are available online. To view these files please visit the journal online (http://dx.doi.org/10.1136/ bmjopen-2013-002720).

Received 13 February 2013 Accepted 21 March 2013

This final article is available for use under the terms of the Creative Commons Attribution Non-Commercial 2.0 Licence; see http://bmjopen.bmj.com

${ }^{1}$ School of Paediatrics and Reproductive Health, University of Adelaide, North Adelaide, Australia

${ }^{2}$ Research and Evaluation Unit, Women's and Children's Health Network, North Adelaide, Australia

${ }^{3}$ Child and Family Health Service Division, Women's and Children's Health Network, Adelaide, Australia ${ }^{4}$ Discipline of Public Health, School of Population Health, University of Adelaide, Adelaide, Australia

${ }^{5}$ School of Social and Community Medicine, University of Bristol, Bristol, UK

Correspondence to Professor Michael Gifford Sawyer; michael.sawyer@adelaide. edu.au

\section{ABSTRACT}

Objective: To evaluate the effects of a postnatal home-visiting programme delivered by community health nurses to socially disadvantaged mothers in South Australia.

Design: The intervention group of 428 mothers lived in metropolitan Adelaide and the comparison group of 239 mothers lived in regional towns where the programme was not yet available. All participating mothers met health service eligibility criteria for enrolment in the home-visiting programme.

Participants in both groups were assessed at baseline (mean child age $=14.4$ weeks $S D=2.3$ ), prior to programme enrolment, and again when the children were aged 9, 18 and 24 months.

Setting: State-wide community child health service. Participants: 667 socially disadvantaged mothers enrolled consecutively. 487 mothers $(73 \%)$ completed the 24-month assessment.

Intervention: Two-year postnatal home-visiting programme based on the Family Partnership Model.

Primary outcome measures: Parent Stress Index (PSI), Kessler Psychological Distress Scale and the Ages and Stages Questionnaire.

Results: Mixed models adjusting for baseline differences were used to compare outcomes in the two groups. The mothers in the home-visiting group reported greater improvement on the PSI subscales assessing a mother's perceptions on the quality of their relationship with their child $(1.10,95 \% \mathrm{Cl} 0.06$ to $2.14)$ and satisfaction with their role as parents $(0.46$, $95 \% \mathrm{Cl}-0.15$ to 1.07$)$ than mothers in the comparison group. With the exception of childhood sleeping problems, there were no other significant differences in the outcomes across the two groups.

Conclusions: The findings suggest that home-visiting programmes delivered by community health nurses as part of routine clinical practice have the potential to improve maternal-child relationships and help mothers adjust to their role as parents.

Clinical Trial Registration: Australian and New Zealand Clinical Trials Registry ACTRN12608000275369.

\section{INTRODUCTION}

During the last decade, services delivered in homes by trained nurses have increasingly been used to enhance parent-child

\section{ARTICLE SUMMARY}

Article focus

- Efficacy trials have reported positive outcomes from home-visiting programmes delivered by nurses to socially disadvantaged mothers and young children.

- There is limited information about the effects of home-visiting programmes when delivered as part of routine clinical practice by nurses in community health services.

- This study evaluated the effects of a postnatal home-visiting programme delivered in routine practice by nurses working in a population-wide community child health service.

\section{Key messages}

- Postnatal home-visiting by nurses in a community child health service improved the mothers' perceptions of mother-child relationships and satisfaction with their parental role.

- Postnatal home-visiting by nurses in a community child health service did not improve maternal mental health or reduce prevalence of maternal health-risk behaviours.

Strengths and limitations of this study

- It was not possible to randomly assign mothers to the intervention and control groups. Despite the baseline adjustment for observed differences, it is possible that other unmeasured differences confounded outcomes across the two study groups.

- Consistent with eligibility criteria, those who participated in this programme were more socially disadvantaged than the general population. However, in areas such as parenting self-efficacy and maternal mental health, they did not differ greatly from mothers in the general community. As a result, there may be limited possibility of enhanced maternal functioning in these areas.

- Although nurses received substantial training and ongoing supervision, it is possible that programme delivery within the context of normal service delivery was unable to maintain adequate levels of fidelity.

relationships and the quality of children's home environments. ${ }^{1-5}$ Although the specific 
nature and content of the services vary, their common feature is the use of trained nurses to deliver homebased services to mothers and young children. The expectation is that if improvements are achieved in areas such as the quality of maternal-child relationships and maternal parenting, this will lead to subsequent improvements in children's development.

Although several comprehensive reviews have concluded that home-visiting services can benefit mothers and young children, ${ }^{1-5}$ a limitation of most evaluations is that they are efficacy trials that assess outcomes in circumstances where research teams are responsible for both service delivery and programme evaluation. ${ }^{1-5}$ Only a small number of effectiveness trials of homevisiting services have been conducted..$^{6-12}$ Additionally, there is little information about the extent to which home-visiting services actually reach disadvantaged mothers. There are only two large-scale evaluations in community settings which account for all potential participants across targeted regions. ${ }^{5} 68$

The aim of the present study was to evaluate the effects of a home-visiting programme delivered to socially disadvantaged mothers by community nurses as part of routine clinical practice in a State-wide community child health service.

\section{METHODS}

\section{Overview of research design}

The evaluation took advantage of a natural experiment created by differential geographic coverage of the South Australian Family Home-Visiting (SA-FHV) programme. At that time, a State-wide universal screening programme identified eligible mothers for enrolment in the SA-FHV programme. However, the programme was available only for mothers living in Adelaide, the major metropolitan city in the State, due to the need to train additional nurses before it could be implemented in regional towns. This provided the opportunity to compare outcomes across two groups of mothers, all of whom met the criteria for enrolment in the SA-FHV programme, but only one group received the programme (see online supplementary table S1 for enrolment criteria).

\section{Participant recruitment}

In South Australia, community nurses visit approximately $90 \%$ of mothers in their homes during the weeks following their child's birth. During the visit, the nurses complete infant health checks and screen mothers for their eligibility to participate in the SA-FHV programme. The present study enrolled mothers who were screened between March 2008 and September 2009.

In the metropolitan region, 2897 mothers were identified as being potentially eligible for the SA-FHV programme (from approximately 23300 births). Following case review, 1936 of these mothers were offered places and 1266 accepted the offer. In regional areas, 522 mothers (from approximately 5200 births) were identified as being eligible for the SA-FHV programme, but could not be offered the programme as it was not yet available in their area.

Due to logistical issues within the health service, contact details for 352 mothers in the metropolitan area and 116 mothers in regional areas were not available for a baseline assessment before their children were aged 12 weeks (the latest age for enrolment in the SA-FHV programme). Twenty-five mothers were leaving South Australia or were no longer caring for their children and were excluded. A further 113 mothers were excluded as they did not speak English. This left 1182 mothers (789 in the metropolitan region and 393 in regional areas) available to participate in the evaluation (figure 1). Assessments of mothers and children were undertaken at baseline (mean age $=14.4$ weeks, $\mathrm{SD}=2.1$ weeks) and again when they were aged 9, 18 and 24 months. The number of participants who completed each assessment is shown in figure 1 .

\section{SA-FHV programme}

The SA-FHV programme aimed to improve the quality of mother-infant relationships, provide anticipatory guidance about infant health, safety and development and better connect families to local community supports.

Specific goals of the SA-FHV programme ${ }^{13}$ were to

1. Enhance the mental and physical health of the children and their families.

2. Enhance the cognitive, social and emotional wellbeing of the children and their families.

3. Assist families to provide a safe and supportive environment for their children.

4. Better link families to available resources and networks within the community.

5. Offer an evidence-based, acceptable and culturally appropriate home-visiting programme.

Content of the SA-FHV programme is broadly similar to that of the postnatal components of the Family Nurse Partnership and the Nurse-Family Partnership programmes in the UK and the USA, ${ }^{11} 1415$ (see online supplementary table S2 for more details). The theoretical base of the programme was the Family Partnership Model. ${ }^{13} 16$

\section{Measures}

The measures used to assess each SA-FHV goal were

1. Mental and physical health, cognitive, social and emotional well-being of children: Children's social and emotional development was assessed using the Ages and Stages Questionnaire: Social and Emotional Questionnaire (ASQ:SE). ${ }^{17}$ The number of items on the ASQ:SE range from 19 items on the 6-month questionnaire to 26 items on the 24-month questionnaire. Consistent with this, mean scores are generally higher for older children. All the questionnaires use a three-point response scale with responses labelled 'most of the time', 'sometimes' or 'rarely or never'. Total scores 
Figure 1 Flow diagram of study participants.

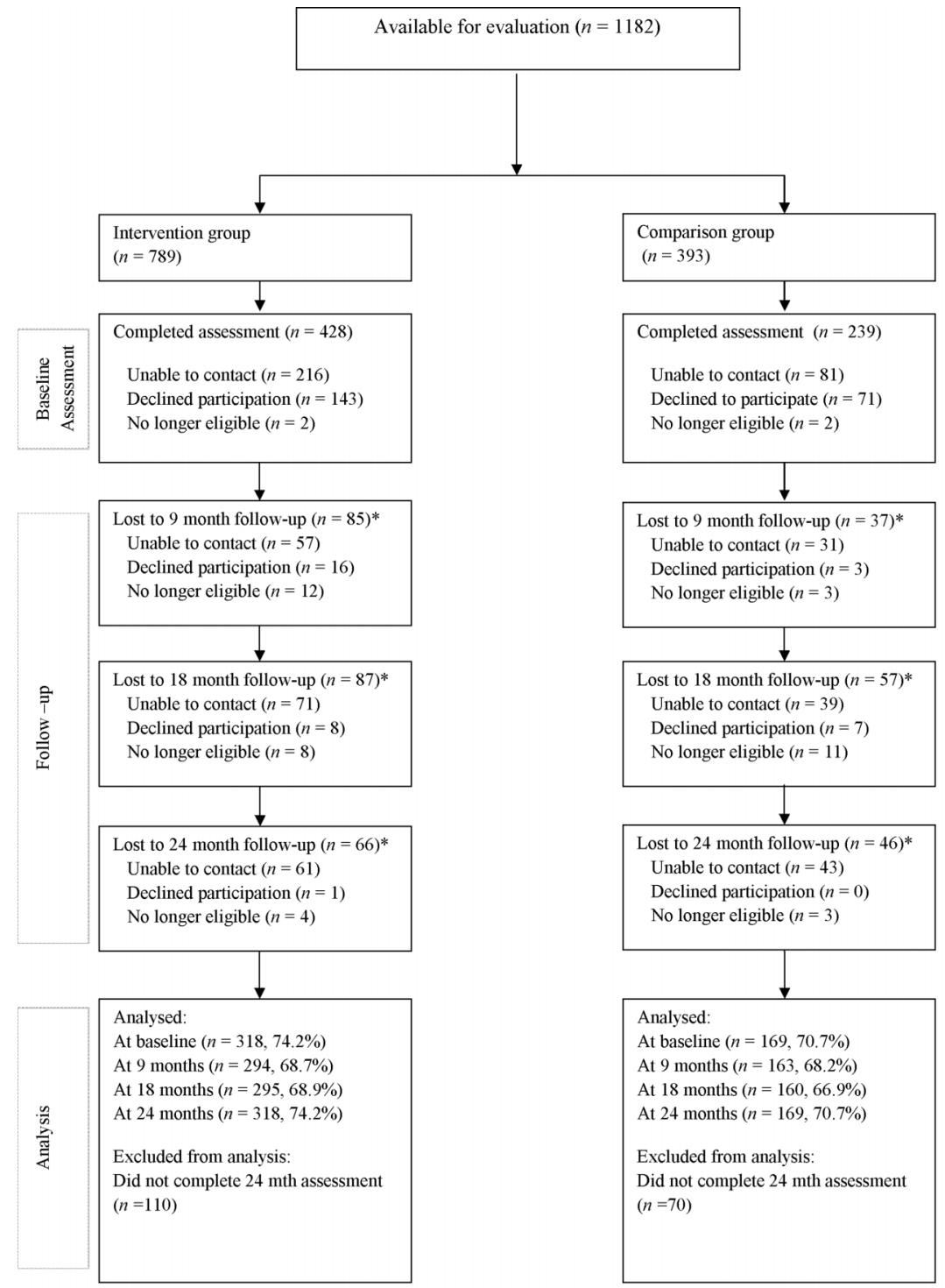

"A small number of mothers who did not complete their 9 month or 18 month assessment, did complete subsequent assessments. They were ineluded in the analysis if they completed the 24 month assessment. are summed with higher scores indicating more problems. ${ }^{17}$ Childhood sleeping and feeding problems and childhood accidents were assessed using standard items employed in the Longitudinal Study of Australian Children (LSAG). ${ }^{18}$

2. Mental and physical health, and cognitive, social and emotional well-being of families: Maternal mental health was assessed using the 10-item Kessler Psychological Distress Scale (K-10), a measure of non-specific psychological distress during the past 4 weeks. The K-10 has been widely used in survey research and has satisfactory psychometric properties. ${ }^{19}$ Maternal alcohol and cigarette use were assessed using standard items employed in the LSAC. ${ }^{18}$

3. Assist families to provide a safe and supportive environment for their children: The quality of parenting was assessed using three subscales from the Parent Stress Index (PSI). ${ }^{20}$ The mothers completed the
PSI Attachment and Role Restriction subscales at all assessments. To reduce participant burden, the Competence subscale was not included at the 9-month assessment. On each subscale, items consist of statements with a five-point response scale. Endpoints were labelled 'Strongly Agree' and 'Strongly Disagree'. The total score is summed with higher scores indicating greater problems.

4. Better link families to the available resources and networks within the community: Use of child and parent services were assessed using standard items employed in the LSAC. ${ }^{18}$

5. Offer an evidence-based, acceptable and culturally appropriate home-visiting programme. Fidelity of the SA-FHV programme was assessed using records of home-visits recorded on an administrative database maintained by the South Australian community child health service responsible for delivering the programme. 


\section{Data collection}

Data collection was undertaken by trained research assistants who visited family homes, where study questionnaires were completed by the mothers.

\section{Statistical analysis}

For outcomes measured using a continuous score, mixed linear regression models were employed to assess group differences in outcomes over time. When outcomes were measured as a binary variable (eg, comparisons of the percentage of individuals who scored above/ below recommended cut-offs), generalised estimating equations with appropriate distributions and link functions were used. Models included main effects for group (intervention vs control), time (3, 9, 18 and 24 months) and a group $\times$ time interaction to assess group differences using all the data collection waves over time. For brevity, only the $p$ values describing the statistical significance of main effects for group and time, and the group $\times$ time interaction are shown in each table. All the analyses were adjusted for relevant baseline covariates (ie, infant age, gender, Aboriginal status, maternal age, level of maternal/paternal education, paternal occupation, number of children, number of parents in household, type of housing and number of home moves in previous 12 months) and the results tables report adjusted scores. The analysis used SAS V.9.2. ${ }^{21}$

The analyses in the manuscript report outcomes for the 318 mothers in the SA-FHV group and 169 mothers in the comparison group who completed the 24-month assessments. Among these, $88 \%$ in the SA-FHV group and $92 \%$ in the comparison group completed all four assessments. Three sensitivity analyses were undertaken to test the robustness of these findings: (1) the mothers who completed at least one assessment, in effect using all available data (SA-FHV group, $\mathrm{n}=428$; comparison group, $n=239$ ), (2) the mothers who completed at least $65 \%$ of planned SA-FHV visits (SA-FHV group, $\mathrm{n}=170$; comparison group, $\mathrm{n}=169$ ) and (3) the mothers who completed all four assessments (SA-FHV group, $n=279$; comparison group, $n=156$ ). As the pattern of results from all analyses was very similar, only analyses involving mothers who completed the 24-month assessment are reported. Results from the three sensitivity analyses are shown in online supplementary tables S3-S5.

\section{Ethics}

The study protocol was approved by the Women's and Children's Hospital Human Research Ethics Committee.

\section{RESULTS}

\section{Participant characteristics}

At the baseline assessment, a higher proportion of mothers in the SA-FHV group were aged $<20$ years, having their first child and were Aboriginal (table 1 and online supplementary table S6 for full sample). They were also more frequently living with friends or relatives and moved home $\geq 2$ times during the previous 12 months. As compared with mothers who completed the evaluation, those lost to follow-up were more commonly Aboriginal and aged $<20$ years. They had also completed fewer years at school, more often lived in rental properties and more often moved home prior to enrolment in the SA-FHV programme (see online supplementary table S7). The criteria used to identify children and mothers in each group were identical (see online supplementary table S1). However, it is possible that nurses in the two regions interpreted the criteria differently and this gave rise to differences across the two groups of mothers and children.

\section{SA-FHV programme completion rates}

The percentage of planned home-visits completed by participants in the SA-FHV programme and the percentage of families that were actively receiving services when children were aged 9,18 and 24 months are shown in online supplementary table S8. Slightly less than $70 \%$ of mothers received home visits for the full 2 years of the programme. However, only $53 \%$ of mothers had received $>65 \%$ of the programmed visits. The mean number of visits received by mothers was $21(\mathrm{SD}=9)$.

\section{Evaluation outcomes}

At the baseline assessment, mean scores on all three PSI subscales were higher (indicating worse functioning) in the SA-FHV group than in the comparison group (table 2). On the PSI Attachment and Role Restriction Subscales, scores in the SA-FHV group declined more across the 2 years of the study (indicating improved functioning) than in the comparison group. This was reflected in the group $\times$ time $p$ values $(p=0.03$ and $p=0.006)$ which show that the linear trajectories of these scores over time differed in the two groups, with greater improvement evident in the intervention than comparison group, although on both subscales the intervention group had lower scores at each assessment than the comparison group.

At the baseline assessment, children in the SA-FHV group had higher mean scores (indicating worse functioning) on the ASQ:SE than those in the comparison group (table 3). Over the 2 years of the study, the scores in the SA-FHV group increased lesser than the scores in the comparison group (table 3). This suggests that the initial difference in social and emotional development that was evident across the groups at the baseline assessment was gradually reducing over time. At the baseline assessment, there were also substantial differences in the percentage of children who had sleeping problems and feeding problems across the SA-FHV and comparison groups (table 3). In each case, a higher percentage of children were reported as having problems in the SA-FHV group. Over the 2 years of the study, there was an increase in the comparison group in reports of sleeping problems. A smaller increase was reported by the mothers in the SA-FHV group. The percentage of 
Table 1 Baseline demographic characteristics of mothers and children

\begin{tabular}{|c|c|c|c|}
\hline & $\begin{array}{c}\text { SA-FHV } \\
n=318\end{array}$ & $\begin{array}{l}\text { Comparison } \\
\mathrm{n}=169\end{array}$ & p Value* \\
\hline \multicolumn{4}{|l|}{ Children } \\
\hline Mean age (SD) weeks & $14.1(2.1)$ & $14.9(2.4)$ & $<0.001$ \\
\hline \multicolumn{4}{|l|}{ Gender (\%) } \\
\hline Male & 56.0 & 54.4 & 0.75 \\
\hline Aboriginal (\%) & 16.4 & 7.1 & 0.004 \\
\hline \multicolumn{4}{|l|}{ Mothers } \\
\hline Mean age (SD) years & $26.0(7.6)$ & $28.3(6.6)$ & 0.001 \\
\hline Under 20 (\%) & 25.9 & 10.7 & $<0.001$ \\
\hline Education (\%) & & & 0.58 \\
\hline Completed primary school & 42.1 & 38.5 & \\
\hline Completed high school & 16.1 & 19.5 & \\
\hline Tertiary education & 41.8 & 42.0 & \\
\hline Number of children (\%) & & & $<0.001$ \\
\hline 1 & 69.7 & 37.9 & \\
\hline 2 or more & 30.3 & 62.1 & \\
\hline Parents living with child (\%) & & & 0.02 \\
\hline Two parents & 77.7 & 84.6 & \\
\hline Single mother & 17.0 & 14.8 & \\
\hline Other & 5.3 & 0.6 & \\
\hline \multicolumn{4}{|l|}{ Housing } \\
\hline Current housing (\%) & & & 0.002 \\
\hline Rental & 47.6 & 48.5 & \\
\hline Own home & 33.1 & 44.4 & \\
\hline Living with friends or relatives & 16.1 & 6.5 & \\
\hline Other & 3.2 & 0.6 & \\
\hline Moved house $>2$ times in previous 12 months (\%) & 20.2 & 12.4 & 0.03 \\
\hline
\end{tabular}

children who had accidents requiring medical attention increased in a similar way in each group.

At the baseline assessment, mean K-10 scores in both groups were on the border of the categories defined as 'low' and 'moderate' levels of distress. ${ }^{19} 22{ }^{23}$ Mean K-10 scores were similar in the two groups with scores in both groups declining over time (table 4). At the baseline assessment, the mothers in both groups reported similar rates of heavy cigarette smoking ( $>11$ cigarettes/day) and binge drinking ( $>3$ standard drinks) during the previous year (table 4). In each group, there was little change in the prevalence of cigarette smoking. The frequency of monthly alcohol use increased by approximately $10 \%$ in each group with the rate of the increase being somewhat steeper in the comparison group over the 2 years of the study (table 4 ).

There were no statistically significant differences between the use of child and parent services by families in the SA-FHV and comparison groups (table 5).

\section{DISCUSSION}

The results from this study suggest that postnatal homevisiting, provided as part of routine clinical practice by nurses in community child health services, may improve the disadvantaged mother's perceptions of the quality of their relationship with their child, and satisfaction with their role as parents. However, because these findings were identified in the context of a large number of other outcomes, it is possible that they are chance findings.

Although the size of the differences identified in outcomes between the two study groups were relatively small, they warrant careful attention for several reasons. First, they occurred in areas which the nurses delivering the programme had independently identified as the areas where they considered that mothers received the greatest benefit. ${ }^{24}$ The Family Partnership Model places emphasis on using high-quality nurse-mother relationships to help mothers adapt to their social and psychological circumstances and to enhance mother-child relationships. ${ }^{16}$ It is plausible that the benefits of this approach were reflected in changes to the PSI Attachment and Role Restriction scores. The former assesses the mothers' perceptions of the quality of their relationship with their infant, while the latter assesses the mothers' comfort with their parental role.

Second, the results in the present study are consistent with findings from an earlier randomised controlled trial of a home-visiting programme based on the Family Partnership Model. ${ }^{25}$ In the earlier study, the mothers who received the programme were more sensitive to 
$\underline{\text { Table } 2 \text { Adjusted mean (SE) Parent Stress Index Scale (PSI) scores }{ }^{\star}, \dagger}$

\begin{tabular}{|c|c|c|c|c|c|c|c|}
\hline Scale & Baseline & 9-Month§ & 18-Monthๆ & 24-Month ${ }^{\star *}$ & $\begin{array}{l}\text { Group } \\
\text { p Value }\end{array}$ & $\begin{array}{l}\text { Time } \\
\text { p Value }\end{array}$ & $\begin{array}{l}\text { Groupxtime } \\
\text { p Value }\end{array}$ \\
\hline \multicolumn{8}{|c|}{ PSI competence†† } \\
\hline SA-FHV & $22.5(1.0)$ & - & $21.7(1.0)$ & $21.8(1.0)$ & 0.002 & 0.11 & 0.31 \\
\hline Comparison & $20.0(1.2)$ & - & $19.6(1.2)$ & $20.2(1.2)$ & & & \\
\hline \multicolumn{8}{|l|}{ PSI attachment } \\
\hline SA-FHV & $12.4(0.5)$ & $11.6(0.5)$ & $11.5(0.5)$ & $11.4(0.5)$ & $<0.001$ & $<0.001$ & 0.03 \\
\hline Comparison & $10.8(0.6)$ & $9.9(0.6)$ & $10.8(0.6)$ & $10.5(0.6)$ & & & \\
\hline \multicolumn{8}{|c|}{ PSI role restriction } \\
\hline SA-FHV & $19.7(0.8)$ & $19.0(0.8)$ & $19.4(0.8)$ & $18.6(0.8)$ & 0.01 & $<0.001$ & 0.006 \\
\hline Comparison & $18.4(0.9)$ & $17.0(0.9)$ & $17.9(0.9)$ & $18.3(0.9)$ & & & \\
\hline
\end{tabular}

${ }^{*}$ Higher values indicate a worse outcome on all variables.

†All scores adjusted for infant age, gender and Aboriginal status, maternal age, level of education, number of children, number of parents in household, type of housing and number of home moves in previous 12 months.

¥SA-FHV ( $n=318)$, comparison $(n=169)$.

§SA-FHV ( $n=294)$, comparison $(n=163)$.

ISA-FHV $(n=295)$, comparison $(n=160)$.

${ }^{\star *}$ SA-FHV $(n=318)$, comparison $(n=169)$.

††Two items asking about parents' level of education that comprise part of the PSI Competence subscale were not included in the present study.

SA-FHV, South Australian Family Home-Visiting.

their infant's needs, and infants were more cooperative than mothers and infants who did not receive the programme. However, consistent with the results in the present evaluation, the size of these effects was relatively small and no significant differences were found in outcomes in other areas. ${ }^{25}$ Third, the positive outcomes identified in the present study occurred in areas that have the potential to directly benefit the health and wellbeing of mothers and infants. ${ }^{26}$ As such, small changes in these areas have the potential to have important longterm benefits. Finally, the positive outcomes in the present study were achieved by a home-visiting programme delivered by nurses as part of a routine clinical practice. This increases the likelihood that these outcomes are achievable in regular clinical practice rather than solely in the context of a research trial.

The use of population-level screening highlights the challenges of providing help for all socially disadvantaged mothers identified with problems. During the period of enrolment for the present study, 33\% (619/1906) of mothers who were identified by the screening programme as having substantial problems and who were

Table 3 Adjusted means (SE) and percentages describing child health outcomes*

\begin{tabular}{|c|c|c|c|c|c|c|c|}
\hline & Baseline† & 9-Month‡ & 18-Month§ & 24-Monthๆ & $\begin{array}{l}\text { Group } \\
\text { p Value }\end{array}$ & $\begin{array}{l}\text { Time } \\
\text { p Value }\end{array}$ & $\begin{array}{l}\text { Groupxtime } \\
\text { p Value }\end{array}$ \\
\hline \multicolumn{8}{|l|}{ ASQ:SE score ${ }^{\star *}$} \\
\hline SA-FHV & $25.4(2.4)$ & $23.0(2.4)$ & $26.8(2.5)$ & $27.1(2.5)$ & 0.41 & $<0.001$ & 0.09 \\
\hline Comparison & $20.5(2.8)$ & $22.3(2.8)$ & $26.6(3.1)$ & $27.5(3.0)$ & & & \\
\hline \multicolumn{8}{|c|}{ Sleeping problems (\%) } \\
\hline SA-FHV & 10.0 & 16.3 & 10.1 & 12.7 & 0.94 & $<0.001$ & 0.04 \\
\hline Comparison & 4.9 & 17.2 & 16.1 & 14.5 & & & \\
\hline \multicolumn{8}{|c|}{ Feeding problems (\%) } \\
\hline SA-FHV & 13.1 & 23.5 & - & - & 0.02 & 0.001 & 0.82 \\
\hline Comparison & 6.9 & 14.3 & - & - & & & \\
\hline \multicolumn{8}{|c|}{ Child accidents†† (\%) } \\
\hline SA-FHV & 6.5 & 12.3 & 26.7 & 18.7 & 0.71 & $<0.001$ & 0.78 \\
\hline Comparison & 6.2 & 11.9 & 21.1 & 20.6 & & & \\
\hline
\end{tabular}

${ }^{*}$ All scores adjusted for infant age, gender and Aboriginal status, maternal age, level of education, number of children, number of parents in household, type of housing and number of home moves in previous 12 months.

tSA-FHV $(n=318)$, comparison $(n=169)$.

¥SA-FHV ( $n=294)$, comparison $(n=163)$.

§SA-FHV $(n=295)$, comparison $(n=160)$.

TSA-FHV $(n=318)$, comparison $(n=169)$.

${ }_{\star \star *} A S Q: S E$, Ages and Stages Questionnaire: Social and Emotional. Higher values indicate a worse outcome.

††Parents were asked to report 'accidents or injuries needing medical attention'. These included injuries such as fractures, burns and scalds.

SA-FHV, South Australian Family Home-Visiting. 
Table 4 Adjusted means (SE) and percentages describing maternal health outcomes*

\begin{tabular}{|c|c|c|c|c|c|c|c|}
\hline & Baseline† & 9-Month & 18-Month§ & 24-Monthๆ & $\begin{array}{l}\text { Group } \\
\text { p Value }\end{array}$ & $\begin{array}{l}\text { Time } \\
\text { p Value }\end{array}$ & $\begin{array}{l}\text { Groupxtime } \\
\text { p Value }\end{array}$ \\
\hline \multicolumn{8}{|l|}{$\mathrm{K}-10^{* *}$} \\
\hline SA-FHV & $16.3(0.9)$ & $16.2(0.9)$ & $15.2(0.9)$ & $15.0(0.9)$ & \multirow[t]{2}{*}{0.27} & \multirow[t]{2}{*}{0.02} & \multirow[t]{2}{*}{0.09} \\
\hline Comparison & $15.5(1.1)$ & $14.7(1.1)$ & $15.2(1.1)$ & $14.6(1.1)$ & & & \\
\hline \multicolumn{8}{|c|}{ Currently smokes (\%) } \\
\hline SA-FHV & 28.0 & 29.9 & 27.6 & 27.9 & \multirow[t]{2}{*}{0.80} & \multirow[t]{2}{*}{0.61} & \multirow[t]{2}{*}{0.61} \\
\hline Comparison & 32.4 & 29.7 & 28.4 & 27.2 & & & \\
\hline \multicolumn{8}{|c|}{ Daily smoking $\geq 11$ (\%) } \\
\hline SA-FHV & 8.1 & 6.7 & 7.4 & 6.8 & \multirow[t]{2}{*}{0.96} & \multirow[t]{2}{*}{0.98} & \multirow[t]{2}{*}{0.40} \\
\hline Comparison & 6.1 & 8.3 & 6.9 & 7.4 & & & \\
\hline \multicolumn{8}{|c|}{ Uses alcohol > monthly (\%) } \\
\hline SA-FHV & 65.1 & 70.0 & 69.2 & 71.8 & \multirow[t]{2}{*}{0.49} & \multirow[t]{2}{*}{$<0.001$} & \multirow[t]{2}{*}{0.04} \\
\hline Comparison & 61.0 & 79.5 & 74.8 & 72.2 & & & \\
\hline \multicolumn{8}{|c|}{ Typically $\geq 3$ standard drinks (\%)†† } \\
\hline SA-FHV & 27.8 & 30.9 & 34.3 & 40.4 & \multirow[t]{2}{*}{0.45} & $<0.001$ & \multirow[t]{2}{*}{0.35} \\
\hline Comparison & 26.0 & 41.2 & 38.4 & 43.4 & & & \\
\hline \multicolumn{8}{|c|}{ 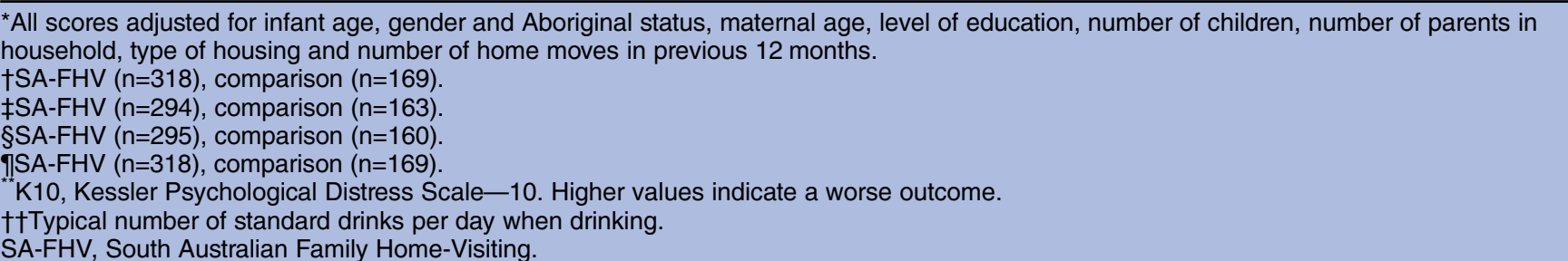 } \\
\hline
\end{tabular}

Table 5 Adjusted percentage of children using child and parent services during the last 12 months*

\begin{tabular}{|c|c|c|c|c|c|c|c|}
\hline Service & Baseline† & 9-Month & 18-Month§ & 24-Monthๆ & $\begin{array}{l}\text { Group } \\
\text { p Value }\end{array}$ & $\begin{array}{l}\text { Time } \\
\text { p Value }\end{array}$ & $\begin{array}{l}\text { Groupxtime } \\
\text { p Value }\end{array}$ \\
\hline \multicolumn{8}{|c|}{ General practitioner (\%) } \\
\hline SA-FHV & 77.0 & 84.9 & 85.7 & 74.0 & 0.76 & $<0.001$ & 0.18 \\
\hline Comparison & 85.0 & 84.3 & 85.2 & 70.0 & & & \\
\hline \multicolumn{8}{|l|}{ Paediatrician } \\
\hline SA-FHV & 38.2 & 31.7 & 16.8 & 9.2 & 0.28 & $<0.001$ & 0.09 \\
\hline Comparison & 24.1 & 29.7 & 13.2 & 9.5 & & & \\
\hline \multicolumn{8}{|c|}{ Emergency department (\%) } \\
\hline SA-FHV & 21.1 & 27.2 & 32.7 & 16.5 & 0.23 & $<0.001$ & 0.65 \\
\hline Comparison & 14.5 & 22.5 & 27.6 & 16.8 & & & \\
\hline \multicolumn{8}{|c|}{ Hospital clinic (\%) } \\
\hline SA-FHV & 15.9 & 12.8 & 9.7 & 9.2 & 0.25 & 0.13 & 0.70 \\
\hline Comparison & 15.7 & 17.5 & 14.0 & 11.8 & & & \\
\hline \multicolumn{8}{|c|}{ Playgroup/parent child group (\%) } \\
\hline SA-FHV & 34.7 & 54.0 & 59.7 & 50.0 & 0.82 & $<0.001$ & 0.12 \\
\hline Comparison & 37.0 & 45.9 & 54.8 & 55.2 & & & \\
\hline \multicolumn{8}{|c|}{ Other services (\%) ${ }^{* *}+\dagger$} \\
\hline SA-FHV & 15.9 & 20.9 & 15.5 & 15.5 & 0.26 & 0.11 & 0.09 \\
\hline Comparison & 14.0 & 13.5 & 18.3 & 9.4 & & & \\
\hline
\end{tabular}

${ }^{*}$ All scores adjusted for infant age, gender and Aboriginal status, maternal age, level of education and number of children unless otherwise indicated.

TSA-FHV ( $\mathrm{n}=318)$, comparison $(\mathrm{n}=169)$.

\#SA-FHV ( $n=294)$, comparison $(n=163)$.

§SA-FHV $(n=295)$, comparison $(n=160)$.

ISA-FHV ( $n=318)$, comparison $(n=169)$.

**'Other services' includes non-general practitioner/paediatric medical services, dental services and other child specific services.

††Due to non-convergence of the full model, this model excluded type of housing.

SA-FHV, South Australian Family Home-Visiting. 
offered a place in the SA-FHV programme, did not enrol in the programme. The major reason for loss of participants in the evaluation was an inability to locate mothers despite the availability of multiple contact details. When this occurred, it was invariably found that the nurses delivering the programme had also lost contact with the mothers. It appears that the screening programme identified a highly mobile group of mothers, and nurses struggled to maintain contact with them for the full 2 years required for programme delivery.

There are several possible reasons for the limited effects achieved by the SA-FHV programme. First, despite baseline adjustment for the observed differences, it is possible that other unmeasured differences confounded outcomes across the two study groups. Second, it is possible that mothers received insufficient dosage of the programme. Although the percentage of mothers who received $\geq 65 \%$ of planned visits was higher than that reported in the $\mathrm{UK},{ }^{14}$ approximately $50 \%$ of mothers in the SA-FHV programme did not reach this level of visitation. Third, although the participants were clearly more socially disadvantaged than the general population, in areas such as parenting self-efficacy and maternal mental health, they did not differ greatly from mothers in the general community. ${ }^{19} 27$ As a result, there may be limited possibility of enhanced maternal functioning in these areas. Finally, although nurses received substantial training and ongoing supervision, it is possible that programme delivery within the context of normal service delivery was unable to maintain adequate levels of fidelity.

\section{CONCLUSION}

This study provides evidence of improvements in mother-child relationships and parental role satisfaction for mothers who participated in a nurse home-visiting programme conducted within the context of populationbased community service delivery. However, there was little evidence of beneficial changes in other areas.

The methodological challenges that confronted this study highlight the importance of new community programmes being established in a manner that allows for a full evaluation of their effectiveness. This is important because the evidence base for new community programmes is often limited. Furthermore, it cannot be assumed that outcomes achieved in efficacy trials will necessarily be achieved in routine clinical practice in community health services. ${ }^{28}$ As such, it is important to give appropriate weight to both programme implementation and programme evaluation at the time new community programmes are initiated.

At a population-level, a major challenge for community programmes is achieving and maintaining changes in core areas of maternal and child functioning of sufficient size to benefit the future health and well-being of mothers and their children. Achieving this requires interventions that can effectively engage large proportions of socially disadvantaged mothers in targeted regions and ensure that they receive sufficient programme 'dosage' to achieve clinically meaningful changes.

Two steps could be used to improve the effectiveness of nurse home-visiting programmes such as the SA-FHV programme. First, SA-FHV selection criteria focused largely on maternal demographic characteristics and nurse perceptions of maternal and child problems. Less emphasis was placed on the extent to which mothers perceived themselves or their child to have problems that could benefit from regular nurse home-visits. It is possible that better engagement and more positive outcomes may be achieved if the selection criteria placed greater emphasis on the extent to which mothers perceive themselves or their children to have problems that might benefit from regular nurse home-visits. A more detailed assessment of this kind was successfully utilised in the Early Start Program described by Fergusson et $a .^{29}$ Second, programme effectiveness may be improved if there were stronger linkages between nursebased and internet-based supports. There are now a wide range of internet-based support programmes for new mothers. ${ }^{30} 31$ However, few of these programmes link with nurse-based services. This is a significant weakness as there is strong evidence that internet-based programmes are being widely used by new mothers. ${ }^{30} 31$ Linking the two approaches may achieve better outcomes than those achieved when the two approaches are provided in isolation from each other.

Acknowledgements Funding for the evaluation was provided by the SA Health Strategic Health Research Program, Australian Rotary Health and the Channel 7 Children's Research Foundation. We would also like to thank all staffs and participants for the support they provided for this project. $\mathrm{JL}$ is supported by an Australia Fellowship from the National Health and Medical Research Council of Australia.

Contributors MGS conceptualised the study, drafted the initial manuscript, analysed and interpreted the data for the study and approved the final manuscript as submitted. LF analysed the data for the study, reviewed and revised the manuscript and approved the final manuscript as submitted. KB helped conceptualise the study, interpret data and reviewed and approved the final manuscript. JL conceptualised the study, interpreted the statistical analysis, reviewed and revised the manuscript and approved the final manuscript as submitted.

Funding This work was supported by the SA Health Strategic Health Research Program (Grant No: CH-11 592), Australian Rotary Health (Grant No: $\mathrm{N} / \mathrm{A}$ ) and the Channel 7 Children's Research Foundation (Grant No: 258).

Competing interests KB is the Director of Child and Family Health Services (CaFHS). CaFHS delivers the South Australian Family Home Visiting programme.

Ethics approval Women's and Children's Hospital Human Research Ethics Committee.

Provenance and peer review Not commissioned; externally peer reviewed. Data sharing statement No additional data are available.

\section{REFERENCES}

1. Azzi-Lessing L. Home visitation programs: critical issues and future directions. Early Child Res Q 2011;26:387-98. 
2. Chaffin M. Is it time to rethink healthy start/healthy families? Child Abuse Negl 2004;28:589-95.

3. Gomby DS. Home visitation in 2005: outcomes for children and parents. Invest in Kids Working Paper No 7: Committee for Economic Development. 2005.

4. Sweet MA, Appelbaum MI. Is home visiting an effective strategy? A meta-analytic review of home visiting programs for families with young children. Child Dev 2004;75:1435-56.

5. Olds DL, Sadler L, Kitzman H. Programs for parents of infants and toddlers: recent evidence from randomized trials. J Child Psychol Psychiatry 2007;43:355-91.

6. Duggan A, McFarlane E, Fuddy L, et al. Randomized trial of a statewide home visiting program: impact in preventing child abuse and neglect. Child Abuse Negl 2004;28:597-622.

7. Duggan A, Windham A, McFarlane E, et al. Hawaii's healthy start program of home visiting for at-risk families: evaluation of family identification, family engagement, and service delivery. Pediatr 2000;105:250-9.

8. Duggan A, Caldera D, Rodriguez $\mathrm{K}$, et al. Impact of a statewide home visiting program to prevent child abuse. Child Abuse Neg 2007;31:801-27.

9. Mitchell-Herzfeld S, Izzo C, Greene R, et al. Evaluation of Healthy Families New York (HFNY): First Year Program Impacts [Internet]. New York, NY: Healthy Families New York. 2005 [cited 2012 Dec 6] http://www.healthyfamiliesnewyork.org/research reports papers.cfm

10. DuMont K, Mitchell-Herzfeld S, Greene R, et al. Healthy Families New York (HFNY) randomized trial: effects on early child abuse and neglect. Child Abuse Negl 2008:32:295-315.

11. Love JM, Kisker EE, Ross C, et al. The effectiveness of Early Head Start for 3-year-old children and their parents: lessons for policy and programs. Dev Psychol 2005;41:885-901.

12. Kemp L, Harris E, McMahon C, et al. Child and family outcomes of a long-term nurse home visitation programme: a randomised controlled trial. Arch Dis Child 2011;96:533-40.

13. Hood M. Home visiting manual. Children youth and women's health service. Adelaide, SA: Government of South Australia, 2007.

14. Barnes J, Ball M, Meadows P, et al. The FNP Implementation Research Team. Nurse-family partnership programme: second year pilot sites implementation in England: the infancy period. London: Institute for the Study of Children, Families and Social Issues, 2009.

15. Barnes J, Ball M, Meadows $\mathrm{P}$, , et al The FNP implementation team. Nurse-family partnership program: first year pilot sites implementation in England: pregnancy and the post-partum period. London: Insititute for the Study of Children, Families and Social Issues, Birbeck, University of London, 2008.
16. Davis H, Day C. Working in partnership: the family partnership model: Pearson. 2010.

17. Squires J, Bricker D, Twombly E. The ASQ:SE user's guide for the ages and stages questionnaires: social-emotional: a parent completed, child-monitoring program for social-emotional behaviors. Baltimore, MD: Paul H Brookes Publishing Company, 2003.

18. Australian Institute of Family Studies. The Iongitudinal study of Australian children annual statistical report 2010. Canberra, ACT: AIFS, 2011.

19. Kessler RC, Barker PR, Colpe LJ, et al. Screening for serious mental illness in the general population. Arch Gen Psychiatry 2003:60:184-9.

20. Abidin RR. Parenting stress ilndex, 3rd edn (PSI). Lutz, FL: Psychological Assessment Resources, 1995.

21. Littell RC, Milliken GA, Stroup WW, et al. SAS system for mixed models. Cary, NC: SAS Institute Inc, 1996.

22. Australian Bureau of Statistics. Information paper: use of the kessler psychological distress scale in ABS health surveys, Australia, 2001. Canberra: Australian Bureau of Statistics, 2003.

23. Australian Bureau of Statistics. National health survey: summary of results, 2007-2008 (Reissue). Canberra: Australian Bureau of Statistics, 2009.

24. Sawyer MG, Barnes J, Frost L, et al. Nurse perceptions of family home-visiting programs in Australia and England. $J$ Paediatr Child Health. Published Online First: 9 April 2013. doi: 10.1111/jpc.12197.

25. Barlow J, Davis H, Mclntosh E, et al. Role of home visiting in improving parenting and health in families at risk of abuse and neglect: results of a multicentre randomised controlled trial and economic evaluation. Arch Dis Child 2007;92:229-33.

26. Scott S. Parenting programs. In: Rutter M, Bishop D, Pine D, et al., eds. Rutter's child and adolescent psychiatry. Oxford, MA: Blackwell, 2008:1046-61.

27. Australian Institute of Family Studies. The Iongitudinal study of australian children (LSAC). Annual statistical report 2011. Melbourne: AIFS, 2012.

28. Ware $\mathrm{JH}$, Hamel MB. Pragmatic trials-guides to better patient care? New Engl J Med 2011;364:18-19.

29. Fergusson DM, Grant $\mathrm{H}$, Horwood J, et al. Randomized trial of the early start program of home visitation. Pediatrics 2005;116:803-9.

30. Khoo K, Bolt P, Babl FE, et al. Health information seeking by parents in the Internet age. J Paediatr Child Health 2008:44: 419-23.

31. Wainstein BK, Sterling-Levis K, Baker SA, et al. Use of the internet by parents of paediatric patients. J Paediatr Child Health 2006;42:528-32. 